\title{
Insulin-like growth factor axis during embryonic development*
}

\author{
Gordon J. Allan ${ }^{1}$, David J. Flint ${ }^{1}$ and Ketan Patel ${ }^{2}$ \\ ${ }^{1}$ Hannah Research Institute, Ayr KA6 5HL, UK; and ${ }^{2}$ Veterinary Basic Sciences, Royal \\ Veterinary College, London NW1 OUT, UK
}

\begin{abstract}
The insulin-like growth factor (IGF) axis has been studied extensively in the developing vertebrate embryo. Knockout experiments have demonstrated that both IGF-I and -II are required for normal development in the mouse embryo, and mRNA and protein expression patterns for both growth factors, together with those for the type I IGF receptor and the six IGF-binding proteins, have been analysed in embryos from different species. Although the unique temporal and spatial expression patterns of these genes indicates important roles for the IGF axis during organ and whole animal development, the variation and complexity of expression makes these roles difficult to unravel. However, one possible mechanism unifying the IGF system in development is programmed cell death (apoptosis), which has been shown to be important in sculpting embryonic tissues, and, in particular, the developing limb bud. In addition, the very early onset of expression of various IGF family members in chicken embryos further emphasizes the fundamental importance of this system in development. This article reviews the work that has been carried out in this area in the context of current understanding of the IGF system.
\end{abstract}

The biological actions of the insulin-like growth factor (IGF) axis are well defined, and include profound effects on the growth and differentiation of most cell types (Hwa et al., 1999). The established components of the IGF system include IGFs (IGF-I and IGF-II), type I and type II IGF receptors, a family of six secreted IGF-binding proteins (IGFBPs), and IGFBP proteases (Fig. 1). IGF-I and IGF-II are very similar small peptides of approximately $7 \mathrm{kDa}$ and similar to insulin in structure. IGFs are expressed ubiquitously and are important mitogens affecting cell growth and metabolism. In addition to endocrine effects exerted by circulating IGFs, locally produced IGFs exert paracrine, as well as autocrine, effects on cell proliferation (Jones and Clemmons, 1995). The IGFs interact with specific cell surface receptors, designated type I and type II IGF receptors, and can also interact with the insulin receptor. The mitogenic effects of IGFs are mediated mainly through interactions with the type I IGF receptor, which has tyrosine kinase activity. The type II IGF receptor is structurally distinct, binds primarily IGF-II, but also serves as a receptor for mannose-6-phosphate-containing ligands (Nissley and Lopaczynski, 1991). The role(s) of the type II receptor in mediating IGF action is less well defined (Kornfeld, 1992).

In biological fluids, IGFs are normally bound by

Email: allang@hri.sari.ac.uk

*This article is based on a presentation given at the British Society of Animal Science symposium 'Early Regulation of Mammalian Development' held in Aberdeen in September 2000. members of a family of secreted IGFBPs of approximately $30 \mathrm{kDa}$. There are, to date, six well characterized mammalian IGFBPs, designated IGFBP-1 to -6 . Since the affinity constants of the IGFBPs are 2-50-fold greater for binding IGFs than that of the IGF type I receptor, they can modulate IGF action by preventing the insulin-like effects of IGFs, controlling the half-life of IGFs in blood, acting as carrier proteins for IGFs and determining the distribution of IGFs between tissues and extracellular fluids (Hwa et al., 1999). The affinity of IGFBPs for IGFs is controlled by phosphorylation, glycosylation and specific proteolysis (Clemmons, 1998). In the prostate, thyroid and mammary glands, the expression of a particular binding protein, IGFBP-5, coincides with a stage during tissue remodelling known as involution, when many cells are removed by programmed cell death (Guenette and Tenniswood, 1994; Phillips et al., 1994; Tonner et al., 1997). It has been proposed that IGFBP-5 triggers the apoptotic process through attenuation of IGF-I, which is necessary for cell survival. This attenuation may occur by sequestration of IGFs bound to IGFBP-5 in the extracellular matrix (ECM).

There is increasing evidence that IGFBPs not only regulate IGF bioavailability, but that they also have their own receptors that mediate IGF-independent actions. Cell surface receptors for IGFBP-1 (Jones et al., 1993), IGFBP-2 (Rauschnabel et al., 1999), IGFBP-3 (Oh et al., 1993a) and IGFBP-5 (Andress, 1995, 1998) have been described, although, to date, none of these proteins have been cloned. Direct IGF-independent effects of IGFBPs include modulation of bone cell proliferation (Mohan et al., 1995) and growth arrest of breast and prostate cancer cells (Oh et 


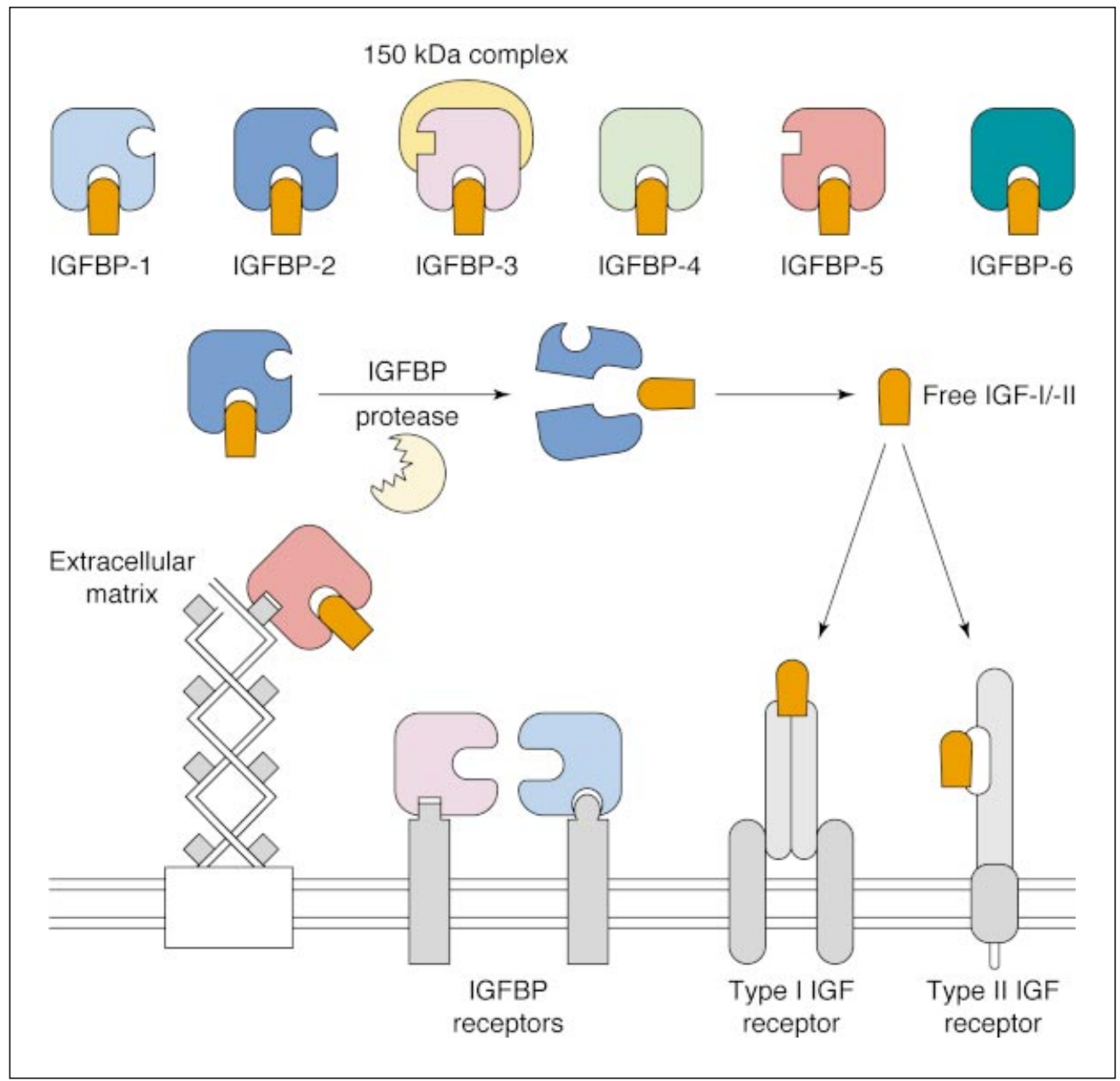

Fig. 1. Components of the insulin-like growth factor (IGF) axis. IGF-binding protein 3 (IGFBP-3) is the main circulatory binding protein and is transported in serum complexed with a glycoprotein. The binding protein and glycoprotein together make up a $150 \mathrm{kDa}$ complex. IGFBPs are secreted proteins and all six have been shown to have autocrine effects in a variety of different cell types. Cell surface receptors have been identified for IGFBP-1, $-2,-3$ and -5 , and several have been shown to bind to the extracellular matrix.

al., 1993a,b, 1995; Rajah et al., 1997). However, owing to the diverse range of properties imparted by the IGFs and IGFBPs, their role during organ and whole animal development has been difficult to unravel.

\section{The IGF axis in development}

The mRNA and protein expression patterns of the various components of the IGF axis have been studied extensively in the developing embryo using in situ hybridization techniques and immunohistochemistry.

\section{Mammalian development}

For many years it was considered that there was a change from IGF-II to IGF-I during fetal to adult growth, as IGF-II is expressed more widely in the embryo (Bhaumick and Bala,
1987). The IGF-II gene is also a member of a small family of genes that have been shown to be subject to genomic imprinting (Reik et al., 1996; Moore et al., 1997). An imprinted gene is expressed primarily from one specific parental allele and such genes have been shown to exert important effects, primarily on fetal development. The use of homologous recombination technology proved conclusively that IGF-II was required for normal embryonic development, as IGF-II null mice (requiring only the disruption of the paternal allele due to parental imprinting) were $60 \%$ smaller than their wild-type littermates (DeChiara et al., 1990, 1991; Fig. 2). These growth-deficient animals were otherwise apparently normal and fertile, demonstrating that IGF-II protein is not essential for development and survival. The phenotype of the null mutant mice was surprising and difficult to reconcile with the fact that IGF-II had been shown to have a specific expression pattern in 
(a) IGF-II knockout
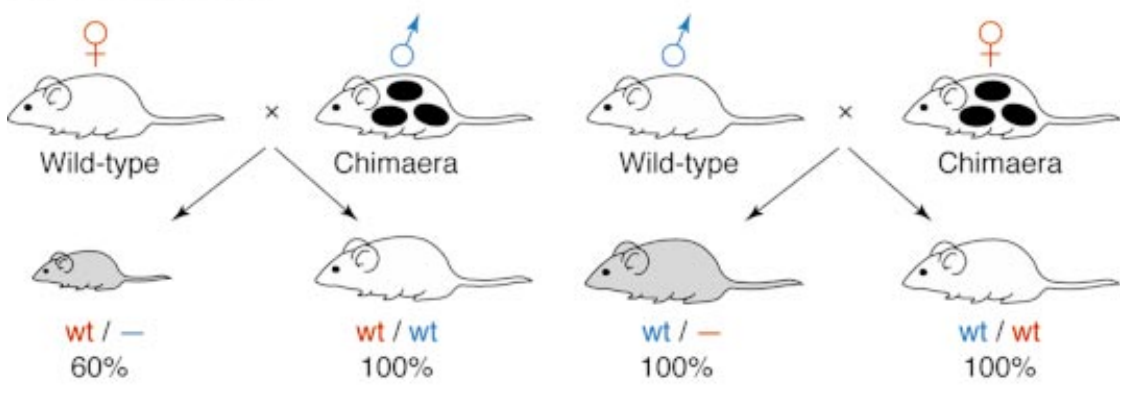

(b) IGF-I knockout

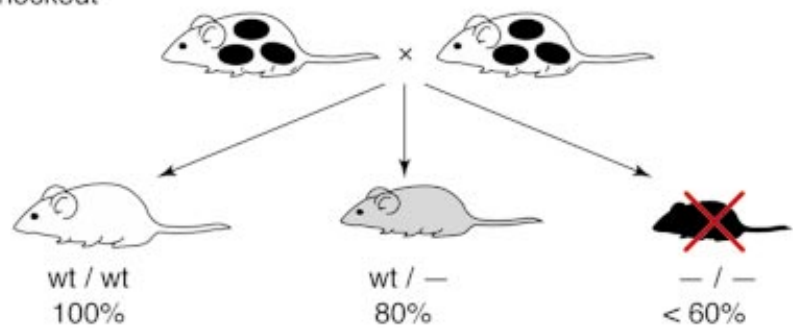

Fig. 2. Insulin-like growth factor I (IGF-I) and IGF-II knockouts cause growth deficiency during embryonic development in mice. (a) Chimaeric mice containing a targeted disruption of one IGF-II allele (DeChiara et al., 1990, 1991). Germline transmission of the inactivated gene from male chimaeras yields heterozygous mutants ( $w t /-$, grey mouse) that are $60 \%$ the size of wild-type ( $w t$, white mouse) littermates. In contrast, when the disrupted gene is transmitted maternally, the heterozygous offspring are phenotypically normal, indicating that the maternal IGF-II allele is silenced by genetic imprinting. (b) Results of crossing chimaeras containing a disrupted IGF-I allele (Powell-Braxton et al., 1993). Heterozygous offspring (grey mouse) are 10-20\% smaller than wild-type littermates (white mouse), whereas homozygous mutants (black mouse) are $<60 \%$ the bodyweight of wild-type mice. In addition, $>95 \%$ of the homozygous mutant pups die perinatally (red cross).

many different tissues throughout the embryo (Wood et al., 1990; Pintar et al., 1991; Streck et al., 1992). However, later experiments showed that mice with both copies of the IGF-I gene knocked out were not only reduced in size to a similar extent, but also displayed severe muscle dystrophy and most (>95\%) of these mice died at birth (Powell-Braxton et al., 1993; Fig. 2). These findings clearly demonstrated that IGF-I is essential for correct embryonic development in mice. The reduction in size of both types of IGF knockout mice indicates a role for IGFs as cell survival factors. In support of this contention, studies in vitro with cells derived from null mutants for IGF-II (Lamm and Christofori, 1998) and the type I IGF receptor (Cui et al., 1997) demonstrated an increased number of apoptotic cells, whereas animals transgenic for IGF-I (Neuenschwander et al., 1996; Leri et al., 1999), IGF-II (Petrik et al., 1999) and the type I IGF receptor (Steller et al., 1996) demonstrated a reduced number of apoptotic cells.

The expression of IGFBPs during embryogenesis has been the subject of investigation in several laboratories. Earlier studies were confined to the mRNA expression patterns of IGFBP-2 in rat embryos and how these compared with the expression of IGF-II (Orlowski et al., 1990; Wood et al., 1990). These studies showed that during the mid-gestational period of rat development, IGF-II and IGFBP-2 expression patterns often overlapped. In general, it appeared that IGFBP-2 expression was either in populations of rapidly dividing cells or in regions that direct the growth and differentiation of neighbouring cells and tissues, indicating that IGFBP-2 may have important roles during development of numerous fetal tissues either by modulating IGF action or by acting independently of the IGFs. However, interaction between IGFBP-2 and IGF-II does not appear to be an essential method for directing autocrine or paracrine growth since the complete genetic ablation of IGF-II (DeChiara et al., 1990, 1991) did not lead to severe deficits near tissues expressing IGFBP-2.

Subsequently, the mRNA expression patterns of the other five IGFBPs were established (Cerro et al., 1993; Schuller et al., 1993; Green et al., 1994): for example, the expression of IGFBP-5 in a rat embryo at day 11.5 is shown (Fig. 3). All of the IGFBPs are expressed at least as early as day 14 in rat embryos, and each IGFBP has a unique pattern of expression, indicating that the members of this family have 


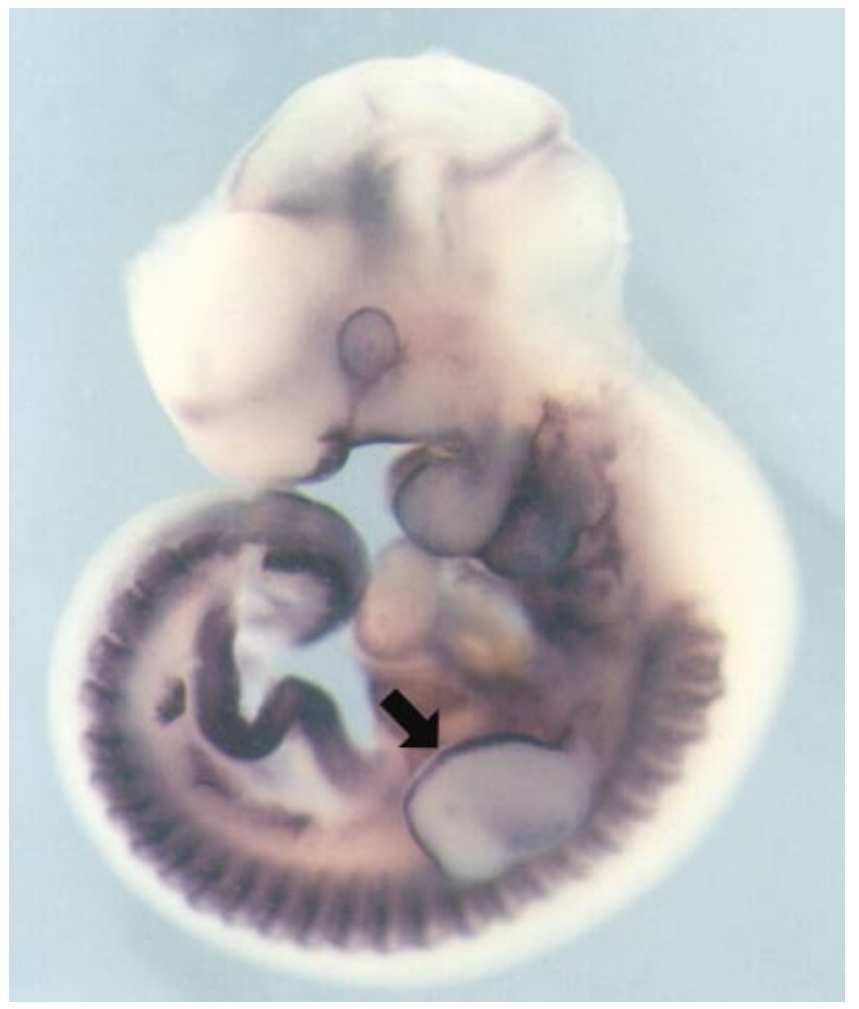

Fig. 3. Whole mount in situ hybridization of an 11.5 day rat embryo showing the expression pattern of insulin-like growth factor binding protein 5 (IGFBP-5) mRNA. Dark blue colour corresponds to sites of message expression, and the arrow indicates the expression of IGFBP-5 in the apical ectodermal ridge of the developing forelimb. The full-length cDNA for rat IGFBP-5, (964 bp), in $p \mathrm{EMM}^{\circledR}-7 \mathrm{zf}$ (Promega), was kindly provided by $\mathrm{S}$. Guenette, John Wayne Cancer Institute, Los Angeles, CA. Conditions for in situ hybridization and processing of embryos were according to Nieto et al. (1996).

distinct and tightly regulated functions in the development of specific tissues. However, IGFBP-2 and -5 display complementary expression patterns that often overlap or occur in adjacent cell populations (Cerro et al., 1993; Schuller et al., 1993; Green et al., 1994). This finding may be indicative of complementary developmental roles for these two binding proteins in specific tissues. Recent immunohistochemical studies using antisera raised against IGFBP-1 to -6 enabled the comparison between IGFBP protein and mRNA localization in mouse embryos (van Kleffens et al., 1999) and demonstrated that differences between mRNA and protein localization were extensive for IGFBP-3, -5 and -6, indicting that these IGFBPs are secreted and transported. In contrast, there was strong overlap of mRNA and peptide for IGFBP-2 and -4, which may indicate an autocrine or paracrine function for these binding proteins (IGFBP-1 mRNA and protein were confined to the liver). In addition, there is significant overlap of IGF axis mRNA expression patterns and regions of apoptotic activity, as measured by Nile blue staining, in both the head-neck region and limb bud (see below) of mouse embryos (van Kleffens et al., 1998). This finding is consistent with the function of IGFs as potent cell survival signals and of IGFBPs as regulators of this function.

\section{Avian development}

In later stages of development in chicken embryos, IGF peptides have been localized immunohistochemically using a polyclonal antibody to human IGF-I, which recognizes both IGF-I and -II (Ralphs et al., 1990). Specific spatiotemporal patterns of expression are similar to those observed in mouse embryos. The cDNA for chicken IGF type I receptor has been cloned and used to generate an anti-sense probe for in situ hybridization, which demonstrated considerable overlap of receptor mRNA expression and the location of the IGF peptides (Holzenberger et al., 1996). In addition, the cDNAs for both chicken IGFBP-5 (Allander et al., 1997) and IGFBP-2 (Schoen et al., 1995a) have also been cloned. In situ hybridization experiments using the chicken IGFBP-2 cDNA as an antisense probe have outlined the expression of IGFBP-2 mRNA in the embryonic eye, brain, branchial arches, somites and limb buds of chicken embryos 3.5 days after mating (Schoen et al., 1995b). The expression patterns are similar to those observed for IGFBP-2 in mouse and rat embryos, indicating that this IGFBP is likely to perform similar functions in both avian and mammalian development.

\section{Linkage of IGFBP and Hox genes}

Each of the human IGFBP genes are localized to the same chromosomal regions as a specific homeobox (Hox) gene family (Allander et al., 1995); for example, IGFBP-2 and -5 are linked to the Hox D gene family on human chromosome 2 in opposite transcriptional orientations. The most likely mechanism to explain this linkage is that IGFBP and Hox genes have co-evolved from a single ancestral genetic locus to multiple loci via the process of chromosomal duplication and translocation (Fig. 4). Whether this tight linkage between the two gene families has any functional significance is unknown, but it is interesting to note that vertebrate Hox genes are well known for their important functions during embryonic development (Krumlauf, 1994).

\section{Limb bud development}

The developing limb bud is an attractive model for studying tissue morphogenesis since a number of key developmental processes are understood at both the cellular and molecular level (Tickle, 1996; Cohn and Bright, 2000; outlined in Fig. $5)$. In vertebrates, limbs develop from paired buds that appear at appropriate points along the main anteroposterior body axis. At early stages, these buds consist of undifferentiated mesenchyme cells encased in ectoderm. At first, limb buds are small mounds (Figs 3 and 5), but these soon elongate. As the buds continue to grow out, they 


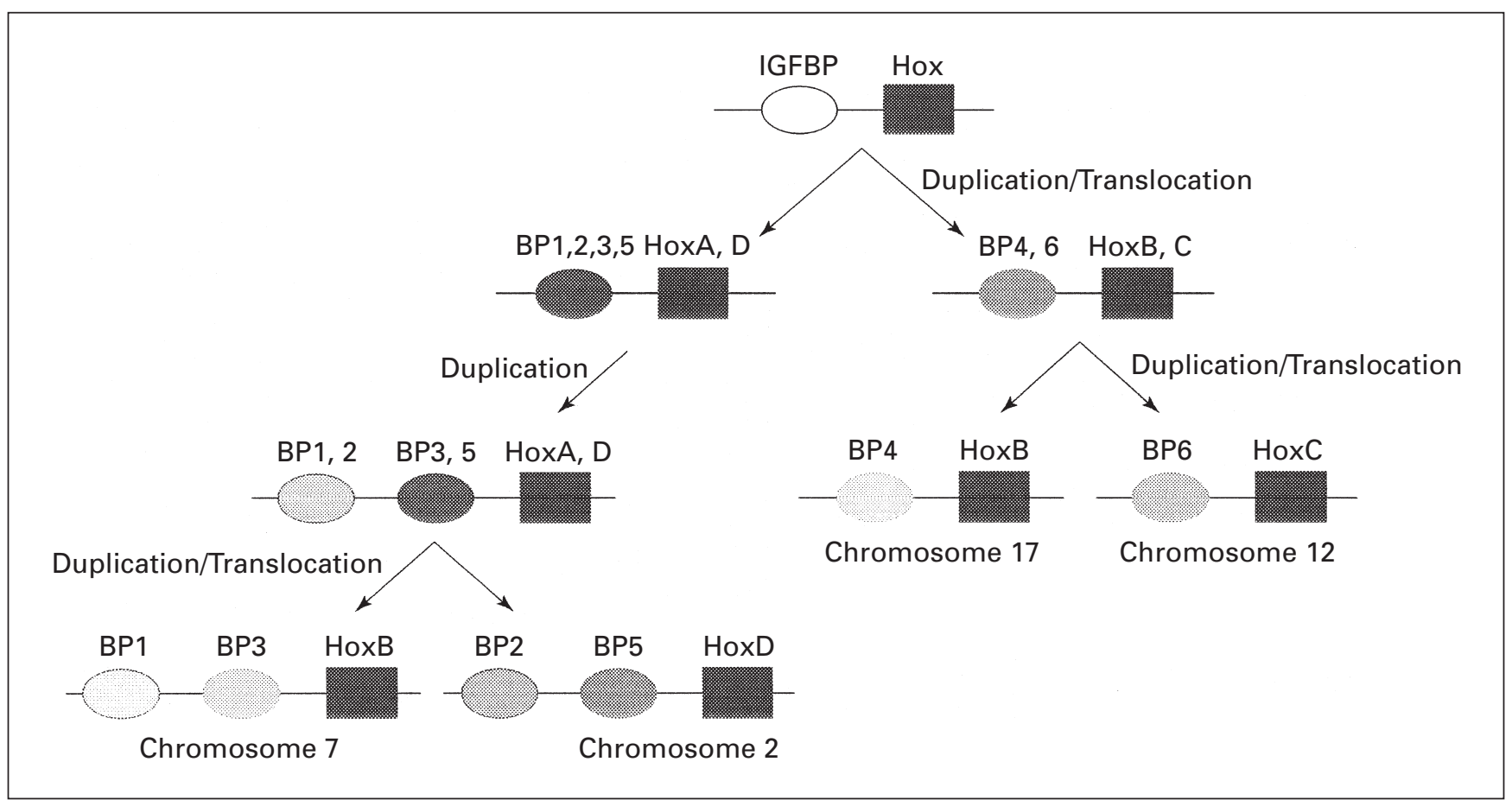

Fig. 4. Co-evolution of the insulin-like growth factor (IGFBP) and Hox gene families. Numbers refer to human chromosomes.

become broader at the tip as digits begin to develop. Later, cells between the developing digits undergo apoptosis. A prominent feature of limb bud development is the reciprocal signalling between the apical ectodermal ridge (AER), which is a region of specialized pseudostratified epithelium covering the distal edge of the developing limb bud, and the underlying undifferentiated mesenchymal cell population, known as the progress zone. The AER is essential for outgrowth of the limb during development, when the mesodermal cells in the progress zone divide more rapidly. Experiments in vitro have confirmed that the AER has a mitogenic effect on limb mesoderm (Tickle, 1996). The polarizing region is an additional signalling region at the posterior margin of the limb mesenchyme, which controls the antero-posterior patterning of the limb bud (Cohn and Bright, 2000). Many experiments have addressed the role of the IGF system during limb development, and these are discussed below.

\section{Expression of the IGF axis in the mammalian embryonic limb bud}

The location of IGF-I and -II expression in the developing limb bud appears to be species dependent. For example, early in rat limb development, IGF-I and -II are expressed throughout the limb mesoderm, but later their expression becomes confined to the proximal part of the bud (Streck et al., 1992). These results indicate that, at least during the early stages of rat limb outgrowth, IGF peptides are available in the region of rapidly proliferating undifferentiated mesoderm at the distal tip of the limb, owing to production within or near that region. It is possible that locally produced IGF peptides are still present in this region during later stages as well, depending on the half-life of the proteins. However, only a proximal location of IGF mRNA in mouse limb buds has been detected (van Kleffens et al., 1998) and an immunohistochemical study has shown that this location coincides with that of IGF peptides (van Kleffens et al., 1999). This discrepancy between rat and mouse limb buds may reflect differences in embryonic stages or the techniques used for detection, and it is possible that, at some point, IGFs are also expressed in the mouse progress zone. In support of this contention, growth of undifferentiated mouse limb bud mesodermal cells has been shown to be stimulated by both IGF-I and IGF-II in vitro (Kaplowitz et al., 1982).

The mouse and rat limb buds provide the most obvious example of the overlap of IGFBP-2 and -5 mRNA expression, with both binding proteins displaying strong expression along the whole length of the AER and weaker expression in a proximal region of the bud (Pintar et al., 1991; Streck et al., 1992; Wood et al., 1992; Allan et al., 1998; van Kleffens et al., 1998; Fig. 3). In fact, IGFBP-2 and -5 are the only two of the six binding proteins expressed in the AER (van Kleffens et al., 1998), and their expression at this site is consistent with them having a role in the directional outgrowth of limb mesenchyme. In addition to IGFBP-2 and -5, several members of the fibroblast growth factor (FGF) family, including FGF-2, -4 and -8 are expressed by the AER (Tickle, 1996). Other factors known to be involved in the apicalsubridge mesoderm interaction are the TGF $\beta$ family 


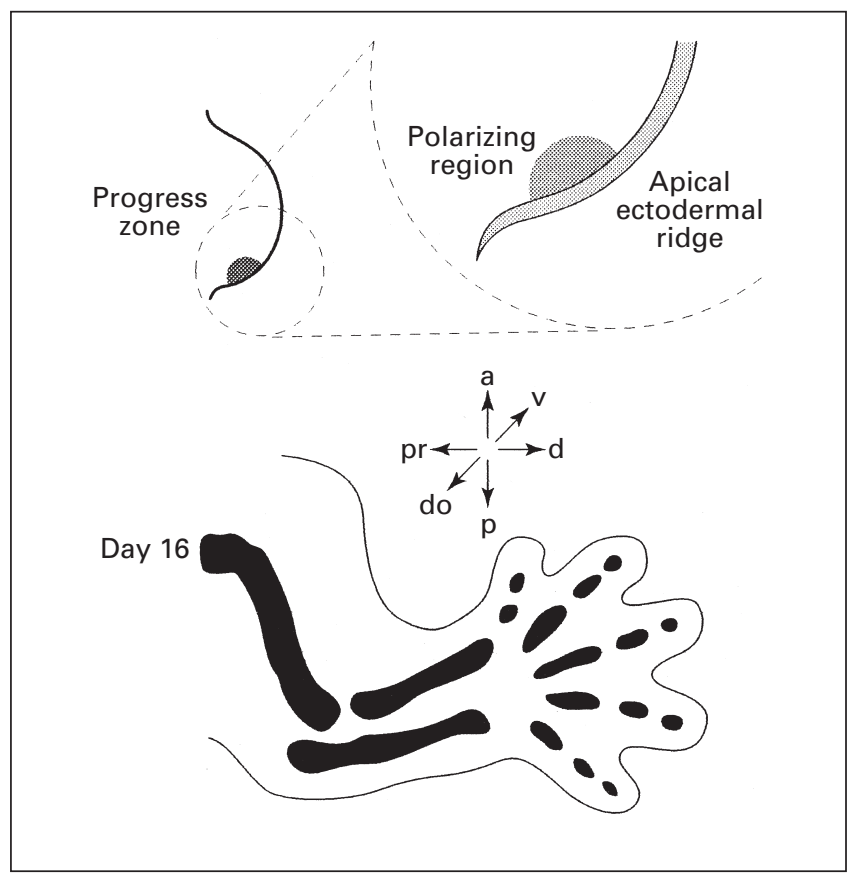

Fig. 5. Development of forelimbs of mouse embryos at 11.5 and 16 days. The signalling regions in the 11.5 day bud are depicted in the expanded segment (circled with dotted line), including the apical ectodermal ridge (AER) and a region of mesenchymal cells responsible for antero-posterior patterning, known as the polarizing region. These signals operate in the undifferentiated mesenchyme immediately below the AER, known as the progress zone. Three main axes are indicated in the centre: pr-d, proximodistal; do-v, dorso-ventral; a-p, antero-posterior.

members known as bone morphogenetic proteins (BMP)-2, -4 and -7 , the homeobox containing transcription factors Msx-1 and -2, as well as some members of the retinoic acid family.

After removal of the AER by apoptosis, the morphology of the digits has to be established. Apoptosis is an important mechanism in sculpting limb morphology and is responsible for removing inter-digital tissue (Milaire, 1992). In addition, programmed cell death may play a role in the positioning of muscle precursors in the limb (Amthor et al., 1998). The BMPs play a major role in the specification of digital and interdigital regions of the limb and may act as apoptotic signals in the presence of Msx and growth factors (Ganan et al., 1996). During this later stage in mouse limb bud development (13.5 days after mating), it was found that most of the IGF system co-localized with areas of apoptosis; IGFBP-2, -4 and -5 were found in the interdigital zone, whereas IGFBP-3 and IGF-I bordered this region (Allan et al, 1998; van Kleffens et al., 1998; Fig. 6 shows expression of IGFBP-5 in the interdigital zone of a mouse forelimb bud 13.5 days after mating). In addition to the limb bud, the IGF system co-localizes to apoptotic regions in the head-neck region of mouse embryos (van Kleffens et al., 1999).

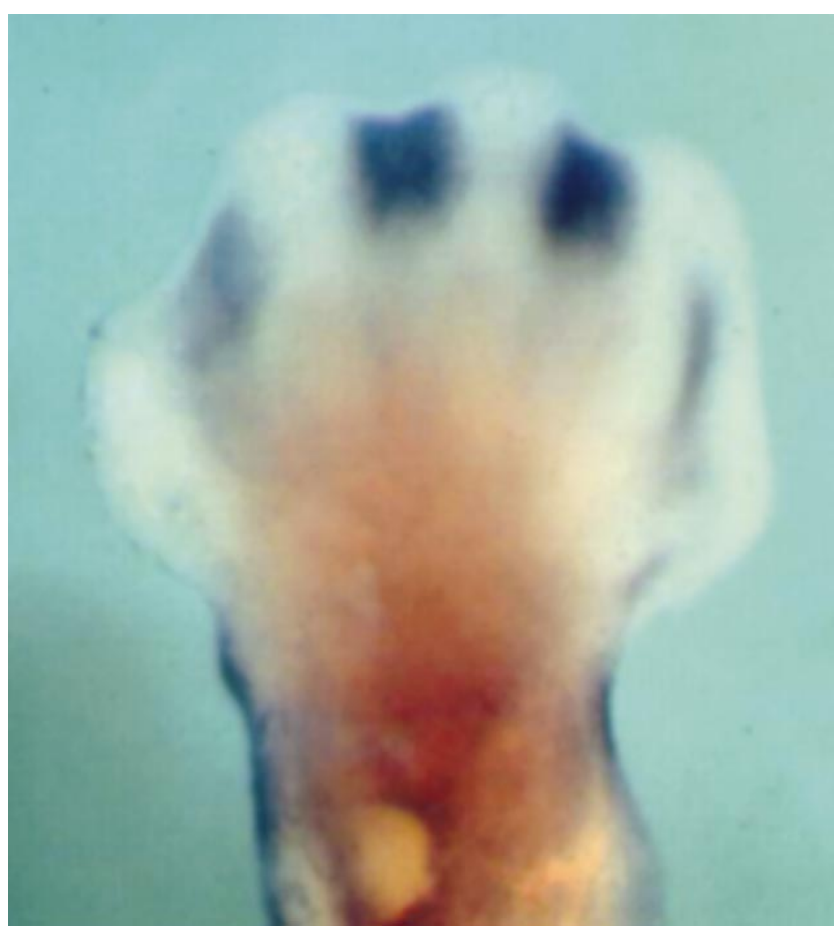

Fig. 6. Whole mount in situ hybridization of mouse embryo forelimb at 13.5 days showing the expression of insulin-like growth factor 5 (IGFBP-5) mRNA (dark blue) in the interdigital zones.

\section{Expression of the IGF axis in the avian wing bud}

Most of the cellular interactions involved in limb morphogenesis are believed to be common for all vertebrates. The later development of the chicken bud is analogous to that of the rat limb bud, in that IGF-I and its receptor are expressed below the AER (Geduspan et al., 1992; Dealy and Kosher, 1995). Although IGF-I does not appear to be expressed in the chicken AER itself, IGF peptides have been detected in the AER by immunohistochemistry (Ralphs et al., 1990), indicating that IGF-I expressed in the subridge mesoderm may be transmitted to the AER. As described above, the mouse and rat AER are sites of strong overlapping expression of both IGFBP-2 and -5 .

Owing to the accessibility of the chicken embryo in the egg, it is feasible to carry out limb bud experiments that involve physical and molecular manipulation. Experiments of this kind have shed further light on the potential role of the IGF axis in limb development. Several lines of evidence point to an IGF-I autocrine regulatory loop in AER-subridge mesoderm interaction. First, both IGF-I and insulin are able to induce a thickened ridge-like structure in the distal anterior ectoderm, raising the possibility that IGF-I or insulin may be involved in the initial induction of AER formation in the limb bud (Dealy and Kosher, 1995). Second, exogenous IGF-I and insulin can promote the outgrowth of limb mesoderm in the absence of the AER (Dealy and Kosher, 1995). In addition, IGF-I expression in the subridge mesoderm is dependent on FGF expression in the AER, and the ability of these FGFs to 
promote the outgrowth and proliferation of limb mesoderm is dependent on IGF-I activity (Dealy et al., 1996). Other lines of evidence link the IGF axis to genes expressed in the AER. First, IGF-I appears to regulate the expression of the homeobox containing transcription factor Msx-2 in the AER (Dealy and Kosher, 1996). Second, studies in bone cell cultures have demonstrated that BMP-2 can enhance IGF-I and -II synthesis and inhibit IGFBP-5 synthesis (Gabbitas and Canalis, 1995).

\section{Alteration of IGF axis expression in Hypodactyly limb buds}

Study of abnormal limb development in mutants has proved very valuable, as it has shed light on the patterning and differentiation processes in limb morphogenesis. During limb development, programmed cell death is essential for the modelling and fine tuning of limb shape (Milaire, 1992), and it is interesting that an alteration in the shape of limb buds is often correlated with changes in the pattern of cell death. The semi-dominant lethal mouse mutant Hypodactyly $(\mathrm{Hd})$, which is caused by a deletion in the Hoxa13 on chromosome 6, develops pointed limb buds that are unlike the paddle shape common to wild-type mice (Hummel, 1970; Mortlock et al., 1996). The Hoxa13 mutation may be a gain of function, as it actually leads to the expression of a mutant HOXA13 protein (Post et al., 2000). Homozygous $(H d / H d)$ pups have only a single 'digit' on both forelimbs and hindlimbs, and usually die in utero. While limb initiation in $\mathrm{Hd}$ embryos appears to be normal, the AER is more pronounced, persists for longer and does not appear to be closely associated with the underlying mesenchyme (Robertson et al., 1996). This abnormal AER may result in a change in reciprocal signalling between ridge and mesenchyme, which could account for the massive increase in cell death in the progress zone observed in Hypodactyly (Robertson et al., 1996). The concomitant reduction of both anterior and posterior mesenchyme in the distal part of the bud results in the distinctive pointed $\mathrm{Hd}$ limb bud. The expression patterns of some of the important limb bud signalling molecules, including sonic hedgehog (Shh), FGF-4, Hoxd13 and Hoxd11, have been analysed in Hd limb buds (Robertson et al., 1997), and it was found that the pattern of transcripts for genes in the mutant did not differ markedly.

We were interested in what other genes might be operating downstream of Hoxa13 that could lead to the phenotype observed in Hypodactyly. As described above, an increase in cell death is observed in $\mathrm{Hd}$ limb buds, indicating that factors involved in apoptosis during limb development may play a part in the manifestation of the $\mathrm{Hd}$ phenotype. The results of our studies using both in situ hybridization and bead implantation, and the detailed study of van Kleffens et al. (1998), indicate strongly that members of the IGF system are involved in the regulation of apoptosis during development of the limb bud. For this reason, we decided to determine whether there was any alteration in the expression patterns of
IGF-I, IGFBP-2 and -5 in heterozygous and homozygous $\mathrm{Hd}$ embryos using in situ hybridization. IGFBP-2 and -5 expression patterns have been found to be altered in the AER in $\mathrm{Hd}$ limb buds, and this is the first example of ridge markers that are affected in this mutant (Allan et al., 2000). IGFBP-2 expression is completely downregulated in the AER as early as 11.5 days after mating, whereas the expression of the gene at more proximal sites was not affected. This would imply that IGFBP-2 is only downregulated in regions where there was mutated Hoxa13 gene transcription. In contrast, IGFBP-5 was only downregulated in specific regions of the AER in $\mathrm{Hd}$ mutants. This alteration in expression indicates that IGFBP-2 and -5 are involved in the manifestation of the mutant phenotype displayed in $\mathrm{Hd}$ limb buds, and adds support to the contention that members of the IGF axis are involved in AER-subridge mesoderm interactions and programmed cell death during limb bud development. In addition, these findings indicate that IGFBP-2 and -5 lie somewhere downstream of Hoxa13 in a signalling pathway. This conclusion is particularly intriguing when the genetic linkage between IGFBP and Hox genes is considered.

\section{The IGF axis in early embryonic development}

The chicken embryo model has the advantage of being accessible from the period of gastrulation through neurulation and organogenesis until hatching. Studies on the expression pattern of the IGF system in early chicken development have been confined to ligand-binding analysis of the IGF type I receptor in chick embryos during gastrulation and neurulation (Bassas et al., 1985; Girbau et al., 1989). An alternative explanation for these expression patterns of the labelled IGFs is that the probe is bound by IGFBPs that are expressed early in development, as the binding proteins have a much greater affinity than the receptor for IGFs (Hwa et al., 1999). However, confirmation that the IGF type I receptor is also expressed at these developmental stages is provided by the findings that IGF-I-dependent tyrosine kinase activity was present in membrane preparations from whole day 2 embryos (Girbau et al., 1989) and that receptor mRNA was detected by polymerase chain reaction (PCR) analysis in chicken blastoderms at day 0 (Scavo et al., 1991). In addition, PCR analysis has demonstrated that IGF-I is expressed in chicken embryos during organogenesis (Serrano et al., 1990). Expression of the IGF type I receptor in chicken blastoderm indicates a potential role for IGF signalling before neurulation or even gastrulation. Since the chicken embryo possesses neither blood circulation nor a liver at these early stages, conceptually, any effects of IGF-I mediated by its receptor are autocrine-paracrine effects.

\section{Conclusions}

Members of the IGF axis have unique temporal and spatial mRNA and protein expression patterns in embryos from different vertebrate species, indicating that these genes have distinct and tightly regulated functions in the development of specific tissues. These expression patterns often co- 
localize with known areas of apoptosis, with the strongest evidence relating to the programmed cell death that occurs in the developing limb bud and, in particular, during the removal of interdigital tissue. These observations are consistent with the function of IGFs as potent cell survival signals and IGFBPs as regulators of this function. Further support for this hypothesis comes from recent work with the mouse mutant Hypodactyly $(H d)$, in which homozygous mutants displayed a large increase in cell death in the limb buds. Loss of expression of both IGFBP-2 and -5 has been observed in the AER of the mutant buds, indicating the involvement of these binding proteins in the manifestation of the mutant phenotype, possibly through their potential to influence apoptosis. Finally, several components of the IGF system are expressed at very early stages of in the chicken embryo, underlining the importance of this gene family in development.

The authors thank Derek Cooney for help with the preparation of this manuscript. This work was partly funded by the Scottish Executive Rural Affairs Department. K. Patel wishes to acknowledge the generous funding provided by the Wellcome Trust (Grant 046379).

\section{References}

Key references are identified by asterisks.

Allan GJ, Flint DJ and Patel K (1998) The role of insulin-like growth factor binding proteins in apoptosis during embryonic limb bud development Abstract from the Epithelial Cell Biology Meeting, Oxford pp 54 Eds P Edwards and C Streuli. British Society for Cell Biology

*Allan GJ, Flint DJ, Darling SM, Geh J and Patel K (2000) Altered expression of insulin-like growth factor 1 and insulin like growth factor binding proteins 2 and 5 in the mouse mutant Hypodactyly $(\mathrm{Hd})$ correlates with sites of apoptotic activity Anatomy and Embryology 202 1-11

Allander SV, Ehrenborg E, Luthman H and Powell DR (1995) Conservation of IGFBP structure during evolution: cloning of chicken insulin-like growth factor binding protein-5 Progress in Growth Factor Research 6 159-165

Allander SV, Coleman M, Luthman H and Powell DR (1997) Chicken insulin-like growth factor binding protein (IGFBP)-5: conservation of IGFBP-5 structure and expression during evolution Comparative Biochemistry and Physiology (B) 116 477-483

Amthor H, Christ B, Weil M and Patel K (1998) The importance of timing differentiation during limb muscle development Current Biology 8 642-652

Andress DL (1995) Heparin modulates the binding of insulin-like growth factor (IGF) binding protein-5 to a membrane protein in osteoblastic cells Journal of Biological Chemistry 27028 289-28 296

Andress DL (1998) Insulin-like growth factor-binding protein-5 (IGFBP-5) stimulates phosphorylation of the IGFBP-5 receptor American Journal of Physiology 274 E744-E750

Bassas L, de Pablo F, Lesniak MA and Roth J (1985) Ontogeny of receptors for insulin-like peptides in chick embryo tissues: early dominance of insulin-like growth factor over insulin receptors in brain Endocrinology $1172321-2329$

Bhaumick B and Bala RM (1987) Receptors for insulin-like growth factors I and II in developing embryonic mouse limb bud Biochimica et Biophysica Acta 927 117-128

Cerro JA, Grewal A, Wood TL and Pintar JE (1993) Tissue-specific expression of the insulin-like growth factor binding protein (IGFBP) mRNAs in mouse and rat development Regulatory Peptides 48 189-198

*Clemmons DR (1998) Role of insulin-like growth factor binding proteins in controlling IGF actions Molecular and Cellular Endocrinology 140 19-24
Cohn MJ and Bright PE (2000) Development of vertebrate limbs: insights into pattern, evolution and dysmorphogenesis. In Development, Growth and Evolution pp 1-28 Eds MJ Cohn and P O'Higgins. The Linnean Society Press, London

Cui SJ, Tewari M, Schneider T and Rubin R (1997) Ethanol promotes cell death by inhibition of the insulin-like growth factor I receptor A/cohol Clinical Experimental Research 21 1121-1127

Dealy CN and Kosher RA (1995) Studies on insulin-like growth factor I and insulin in chick limb morphogenesis Developmental Dynamics 202 67-79

Dealy CN and Kosher RA (1996) IGF-I and insulin in the acquisition of limbforming ability by the embryonic lateral plate Developmental Biology 177 291-299

Dealy CN, Clarke K and Scranton V (1996) Ability of FGFs to promote the outgrowth and proliferation of limb mesoderm is dependent on IGF-I activity Developmental Dynamics 206 463-469

DeChiara TM, Efstratiadis A and Robertson EJ (1990) A growth-deficiency phenotype in heterozygous mice carrying an insulin-like growth factor II gene disrupted by targeting Nature 345 78-80

DeChiara TM, Robertson EJ and Efstratiadis A (1991) Parental imprinting of the mouse insulin-like growth factor II gene Cell 64 849-859

Gabbitas B and Canalis E (1995) Bone morphogenetic protein 2 inhibits the synthesis of insulin-like growth factor-binding protein 5 in bone cell cultures Endocrinology 136 2397-2403

Ganan Y, Macias D, Duterque-Coquillaud M, Ros MA and Hurle JM (1996) Role of TGF betas and BMPs as signals controlling the position of the digits and the areas of interdigital cell death in the developing chick limb autopod Development 122 2349-2357

Geduspan JS, Padanilam BJ and Solursh M (1992) Coordinate expression of IGF-I and its receptor during limb outgrowth Developmental Dynamics $19567-73$

Girbau M, Bassas L, Alemany J and de Pablo F (1989) In situ autoradiography and ligand-dependent tyrosine kinase activity reveal insulin receptors and insulin-like growth factor I receptors in prepancreatic chicken embryos Proceedings National Academy of Sciences USA 86 5868-5872

Green BN, Jones SB, Streck RD, Wood TL, Rotwein P and Pintar JE (1994) Distinct expression patterns of insulin-like growth factor binding proteins 2 and 5 during fetal and postnatal development Endocrinology 134 954-962

Guenette RS and Tenniswood M (1994) The role of growth factors in the suppression of active cell death in the prostate: an hypothesis Biochemistry and Cell Biology 72 553-559

Holzenberger M, Lapointe F, Leibovici $\mathbf{M}$ and Lievre CA (1996) The avian IGF type 1 receptor: cDNA analysis and in situ hybridization reveal conserved sequence elements and expression patterns relevant for the development of the nervous system Developmental Brain Research 97 76-87

Hummel KP (1970) Hypodactyly, a semidominant lethal mutation in mice Journal of Heredity $\mathbf{6 1} 219-220$

Hwa V, Oh Y and Rosenfeld RG (1999) The insulin-like growth factorbinding protein (IGFBP) superfamily Endocrine Reviews 20 761-787

Jones JI and Clemmons DR (1995) Insulin-like growth factors and their binding proteins: biological actions Endocrine Reviews 16 3-34

Jones JI, Gockerman A, Busby WH, Jr, Wright G and Clemmons DR (1993) Insulin-like growth factor binding protein 1 stimulates cell migration and binds to the alpha 5 beta 1 integrin by means of its Arg-Gly-Asp sequence Proceedings National Academy of Sciences USA 90 10 553-10 557

Kaplowitz PB, D'Ercole AJ and Underwood LE (1982) Stimulation of embryonic mouse limb bud mesenchymal cell growth by peptide growth factors Journal of Cell Physiology 112 353-359

Kornfeld S (1992) Structure and function of the mannose 6phosphate/insulin-like growth factor II receptors Annual Reviews in Biochemistry 61 307-330

Krumlauf R (1994) Hox genes in vertebrate development Cell 78 191-201

Lamm GM and Christofori G (1998) Impairment of survival factor function potentiates chemotherapy-induced apoptosis in tumor cells Cancer Research 58 801-807 
Leri A, Liu Y, Wang X, Kajstura J, Malhotra A, Meggs LG and Anversa P (1999) Overexpression of insulin-like growth factor 1 attenuates the myocyte renin-angiotensin system in transgenic mice Circulation Research 84 752-762

Milaire J (1992) A new interpretation of the necrotic changes occurring in the developing limb bud paddle of mouse embryos based upon recent observations in four different phenotypes International Journal of Developmental Biology 36 169-178

Mohan S, Nakao Y, Honda Y, Landale E, Leser U, Dony C, Lang K and Baylink DJ (1995) Studies on the mechanisms by which insulin-like growth factor (IGF) binding protein 4 (IGFBP-4) and IGFBP-5 modulate IGF actions in bone cells Journal of Biological Chemistry 27020424 20431

Moore T, Constancia M, Zubair M, Bailleul B, Feil R, Sasaki H and Reik W (1997) Multiple imprinted sense and antisense transcripts, differential methylation and tandem repeats in a putative imprinting control region upstream of mouse Igf2 Proceedings National Academy of Sciences USA 9412 509-12 514

Mortlock DP, Post LC and Innis JW (1996) The molecular basis of hypodactyly $(\mathrm{Hd})$ : a deletion in Hoxa 13 leads to arrest of digital arch formation Nature Genetics 13 284-289

Neuenschwander S, Schwartz A, Wood TL, Roberts CT, Jr, Henninghausen L and LeRoith D (1996) Involution of the lactating mammary gland is inhibited by the IGF system in a transgenic mouse model Journal of Clinical Investigation 97 2225-2232

Nieto MA, Patel K and Wilkinson DG (1996) In situ hybridization analysis of chick embryos in whole mount and tissue sections Methods in Cell Biology 51 219-235

Nissley P and Lopaczynski W (1991) Insulin-like growth factor receptors Growth Factors 5 29-43

Oh Y, Muller HL, Pham H and Rosenfeld RG (1993a) Demonstration of receptors for insulin-like growth factor binding protein 3 on Hs578T human breast cancer cells Journal of Biological Chemistry 268 $26045-26048$

Oh Y, Muller HL, Lamson G and Rosenfeld RG (1993b) Insulin-like growth factor (IGF)-independent action of IGF-binding protein-3 in Hs578T human breast cancer cells. Cell surface binding and growth inhibition Journal of Biological Chemistry 268 14 964-14971

Oh Y, Gucev Z, Ng L, Muller HL and Rosenfeld RG (1995) Antiproliferative actions of insulin-like growth factor binding protein (IGFBP)-3 in human breast cancer cells Progress in Growth Factor Research 6 503-512

Orlowski CC, Brown AL, Ooi GT, Yang YW, Tseng LY and Rechler MM (1990) Tissue, developmental, and metabolic regulation of messenger ribonucleic acid encoding a rat insulin-like growth factor-binding protein Endocrinology 126 644-652

Petrik J, Pell JM, Arany E, McDonald TJ, Dean WL, Reik W and Hill DJ (1999) Overexpression of insulin-like growth factor-II in transgenic mice is associated with pancreatic islet cell hyperplasia Endocrinology $\mathbf{1 4 0}$ 2353-2363

Phillips ID, Becks GP, Logan A, Wang JF, Smith C and Hill DJ (1994) Altered expression of insulin-like growth factor I (IGF-I) and IGF binding proteins during rat thyroid hyperplasia and involution Growth Factors 10 207-222

Pintar JE, Wood TL, Streck RD, Havton L, Rogler L and Hsu MS (1991) Expression of IGF-II, the IGF-II/mannose-6-phosphate receptor and IGFBP-2 during rat embryogenesis Advanced Experimental Medical Biology 293 325-333

Post LC, Margulies EH, Kuo A and Innis JW (2000) Severe limb defects in Hypodactyly mice result from the expression of a novel, mutant HOXA13 protein Developmental Biology 217 290-300

*Powell-Braxton L, Hollingshead P, Warburton C, Dowd M, Pitts-Meek S, Dalton D, Gillett N and Stewart TA (1993) IGF-I is required for normal embryonic growth in mice Genes and Development 7 2609-2617

Rajah R, Valentinis B and Cohen P (1997) Insulin-like growth factor (IGF)binding protein 3 induces apoptosis and mediates the effects of transforming growth factor-beta1 on programmed cell death through a p53- and IGF-independent mechanism Journal of Biological Chemistry $27212181-12188$

Ralphs JR, Wylie L and Hill DJ (1990) Distribution of insulin-like growth factor peptides in the developing chick embryo Development 109 51-58

Rauschnabel U, Koscielniak E, Ranke MB, Schuett B and Elmlinger MW (1999) RGD-specific binding of IGFBP-2 to alpha 5 beta 1-integrin of Ewing sarcoma cells (Abstract from the 5th International Symposium on Insulin-like Growth Factors, Brighton) Growth Hormone and IGF Research 9369

Reik W, Bowden L, Constancia M, Dean W, Feil R, Forne T, Kelsey G, Maher E, Moore T, Sun FL and Walter J (1996) Regulation of Igf2 imprinting in development and disease International Journal of Developmental Biology Supplement $153 \mathrm{~S}-54 \mathrm{~S}$

Robertson KE, Chapman MH, Adams A, Tickle C and Darling SM (1996) Cellular analysis of limb development in the mouse mutant hypodactyly Developmental Genetics 19 9-25

Robertson KE, Tickle C and Darling SM (1997) Shh, Fgf4 and Hoxd gene expression in the mouse limb mutant hypodactyly International Journal of Developmental Biology 41 733-736

Scavo LM, Serrano J, Roth J and de Pablo F (1991) Genes for the insulin receptor and the insulin-like growth factor I receptor are expressed in the chicken embryo blastoderm and throughout organogenesis Biochemical and Biophysical Research Communication 176 1393-1401

Schoen TJ, Mazuruk K, Waldbillig RJ, Potts J, Beebe DC, Chader GJ and Rodriguez IR (1995a) Cloning and characterization of a chick embryo cDNA and gene for IGF-binding protein 2 Journal of Molecular Endocrinology 15 49-59

Schoen TJ, Bondy CA, Zhou J, Dhawan R, Mazuruk K, Arnold DR, Rodriguez IR, Waldbillig RJ, Beebe DC and Chader GJ (1995b) Differential temporal and spatial expression of insulin-like growth factor binding protein 2 in developing chick ocular tissues Investigative Ophthalmology and Visual Science 36 2652-2662

Schuller AG, Zwarthoff EC and Drop SL (1993) Gene expression of the six insulin-like growth factor binding proteins in the mouse conceptus during mid- and late gestation Endocrinology 132 2544-2550

Serrano J, Shuldiner AR, Roberts CT, Jr, LeRoith D and de Pablo F (1990) The insulin-like growth factor I (IGF-I) gene is expressed in chick embryos during early organogenesis Endocrinology 127 1547-1549

Steller MA, Zou Z, Schiller JT and Baserga R (1996) Transformation by human papillomavirus $16 \mathrm{E} 6$ and E7: role of the insulin-like growth factor 1 receptor Cancer Research 56 5087-5091

Streck RD, Wood TL, Hsu MS and Pintar JE (1992) Insulin-like growth factor I and II and insulin-like growth factor binding protein 2 RNAs are expressed in adjacent tissues within rat embryonic and fetal limbs Developmental Biology $\mathbf{1 5 1} 586-596$

*Tickle C (1996) Genetics and limb development Developmental Genetics 19 1-8

Tonner E, Barber MC, Travers MT, Logan A and Flint DJ (1997) Hormonal control of insulin-like growth factor-binding protein 5 production in the involuting mammary gland of the rat Endocrinology 138 5101-5107

van Kleffens M, Groffen C, Rosato RR, van den Eijnde SM, van Neck JW, Lindenbergh-Kortleve DJ, Zwarthoff EC and Drop SL (1998) mRNA expression patterns of the IGF system during mouse limb bud development, determined by whole mount in situ hybridization Molecular and Cellular Endocrinology 138 151-161

*van Kleffens M, Groffen C, Neck JW, Vermeij-Keers C and Drop SL (1999) mRNA and protein localization of the IGF system during mouse embryonic development in areas with apoptosis Growth Hormone and IGF Research 9 195-204

Wood TL, Brown AL, Rechler MM and Pintar JE (1990) The expression pattern of an insulin-like growth factor (IGF)-binding protein gene is distinct from IGF-II in the midgestational rat embryo Molecular Endocrinology 4 1257-1263

Wood TL, Streck RD and Pintar JE (1992) Expression of the IGFBP-2 gene in post-implantation rat embryos Development 114 59-66 